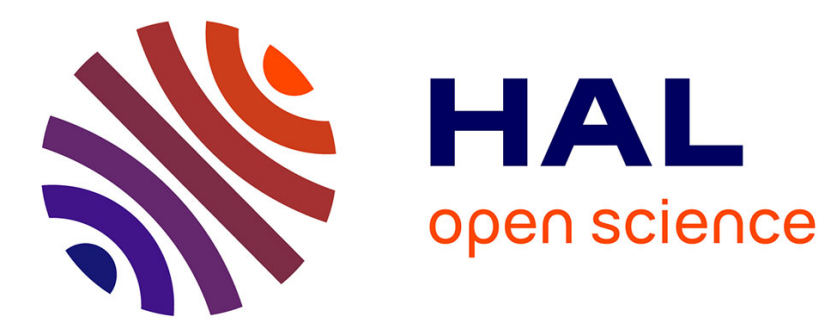

\title{
Numerical and experimental investigations of the influence of the pleat geometry on the pressure drop and velocity field of a pleated fibrous filter
}

Félicie Theron, Aurélie Joubert, Laurence Le Coq

\section{- To cite this version:}

Félicie Theron, Aurélie Joubert, Laurence Le Coq. Numerical and experimental investigations of the influence of the pleat geometry on the pressure drop and velocity field of a pleated fibrous filter. Separation and Purification Technology, 2017, 182, pp.69-77. 10.1016/j.seppur.2017.02.034 . hal01487561

\section{HAL Id: hal-01487561 \\ https://hal.science/hal-01487561}

Submitted on 21 Aug 2019

HAL is a multi-disciplinary open access archive for the deposit and dissemination of scientific research documents, whether they are published or not. The documents may come from teaching and research institutions in France or abroad, or from public or private research centers.
L'archive ouverte pluridisciplinaire HAL, est destinée au dépôt et à la diffusion de documents scientifiques de niveau recherche, publiés ou non, émanant des établissements d'enseignement et de recherche français ou étrangers, des laboratoires publics ou privés. 


\title{
Numerical and experimental investigations of the influence of the pleat geometry on the pressure drop and velocity field of a pleated fibrous filter
}

\author{
Félicie Théron*, Aurélie Joubert, Laurence Le Coq \\ GEPEA, UMR CNRS 6144, IMT Atlantique, CS 20722, 44307 Nantes, France
}

\begin{abstract}
A B S T R A C T
The aim of this study is to combine numerical and experimental approaches to evaluate the influence of pleat geometrical parameters on the pressure drop and air velocity field at the vicinity of pleated fibrous filters. For a given filter, three different geometrical pleat configurations (with various pleat heights and widths) are investigated at similar filtration velocities. Numerical simulations are validated based on experimental measurements in terms of pressure drop versus filtration velocity, and enable the influence of the filter geometry on the air flow pattern in its vicinity to be investigated. The influence of filter geometry on the pressure drop is evaluated from experiments carried out in a lab-scale air handling unit. For this purpose, pleated filter prototypes were designed in the laboratory.
\end{abstract}

Keywords:

Air handling unit

Pleated fibrous filter

Pressure drop

CFD simulations

\section{Introduction}

Today, people living in urban agglomerations spend about $90 \%$ of their time indoors. Currently, environmental and economic considerations are leading to the construction of low energy or positive energy buildings whose envelopes are strongly impermeable. These kinds of "confined microenvironments" need to be properly ventilated to allow air renewal and thus maintain high indoor air quality in terms of humidity, temperature, $\mathrm{CO}_{2}$ level and exposure to air pollutants such as PM2.5 particles. For this purpose, air cleaning is necessary to remove particles, especially from the outdoor air intake in urban areas, and to treat potentially recycled indoor air, which contains mainly volatile organic compounds (VOCs) such as formaldehyde, or PM10 and PM2.5 originating from furniture, paints or people's activities such as cooking. Thus, in-duct air cleaning devices are widely implemented in ventilation systems whose performance management is an important challenge.

Filtration with fibrous filters is the most common technology used in in-duct ventilation systems to remove particles. There are various types of filter with different levels of performance. For example, the European standard EN779-2012 for air filters sorts them into 9 classes (from G1 to F9) based on their average gravimetric efficiency or their lowest filtration efficiency. According to the application, the filters are implemented in ventilation systems in one or several stage(s). The pleated filter is one of the widespread geometrical configurations used to increase the filtration area in the limited space available in air filtration units. The performance of fibrous filters result from the compromise between high efficiency and low pressure drop. In fact, the significant pressure drop generated by the air flow through this process as well as the process maintenance are important economic issues. The design of pleated filters must therefore limit the energy cost of the operation while ensuring the targeted air quality.

Many parameters influence fibrous filters performance: the particle characteristics (size distribution, density, morphology, hygroscopicity, ...), the operating conditions (filtration velocity, air thermodynamic properties), and the filter properties. The latter can be classified by different scales: the fiber scale (fiber crosssectional shape, length, roughness, material, fiber size distribution, length to diameter ratio, ...), the media scale (thickness, fibers arrangement: random or organized, porosity, pore size distribution, local variations in structural parameters due to manufacturing processes, ...), and the filter scale (geometrical properties of the media). It is this third scale that is addressed in the present work. Concerning the pleated filter, these geometrical properties consist of the pleat height, width and opening angle, the pleat number and the resulting filter's developed surface area.

The geometrical properties of the filter may significantly influence local velocities in the pleat vicinity and thus the orders of magnitude of velocity gradients to which particles are submitted. Yet, the air velocity influences the filtration performance at the 


\begin{tabular}{|c|c|c|c|}
\hline B & media permeability $\left[\mathrm{m}^{2}\right]$ & $\mathrm{W}_{\mathrm{m}}$ & mean measured pleat width [m] \\
\hline C & media inertial resistance $\left[\mathrm{m}^{-1}\right]$ & $\mathrm{W}_{\mathrm{t}}$ & theoretical pleat width [m] \\
\hline$D_{f}$ & fiber diameter $[\mathrm{m}]$ & Z & Media thickness [m] \\
\hline $\mathrm{D}_{\mathrm{h}}$ & hydraulic diameter of the duct [m] & & \\
\hline $\mathrm{H}$ & pleat height $[\mathrm{m}]$ & \multicolumn{2}{|c|}{ Greek letters } \\
\hline V & air velocity $\left[\mathrm{m} \cdot \mathrm{s}^{-1}\right]$ & $\varepsilon$ & Media porosity $[-]$ \\
\hline$V_{\text {filtration }}$ & filtration velocity $\left[\mathrm{m} \cdot \mathrm{s}^{-1}\right]$ & $\mu$ & Air dynamic viscosity [Pa.s] \\
\hline $\mathrm{V}_{\text {inlet }}$ & inlet velocity for numerical simulations $\left[\mathrm{m} \cdot \mathrm{s}^{-1}\right]$ & $\rho$ & Air density $\left[\mathrm{kg} \cdot \mathrm{m}^{-3}\right]$ \\
\hline
\end{tabular}

scale of the particle collection mechanisms. In particular, particle collection by Brownian diffusion decreases with increasing filtration velocity, whereas the mechanism of inertial impaction is promoted by increasing filtration velocity.

The aim of the present study is to combine numerical and experimental approaches to evaluate the pressure drop and velocity field of pleated fibrous filters, and especially the local velocity variations, in order to identify trends that could influence the initial local filtration efficiency. It consists of first numerically predicting the initial pressure drop of pleated fibrous filters and experimentally validating the model with various geometries of filters; and secondly, of assessing the influence of filter geometry on the simulated air flow in the vicinity of fibrous pleated filters. The numerical simulations are thus carefully considered in order to reproduce the experimental conditions with the greatest accuracy in terms of the geometrical properties of filters and mean air filtration velocities.

\section{State of the art of numerical studies of air flow in the vicinity of fibrous pleated filters}

The evolution of pleated filter performance during clogging must be evaluated for the design and maintenance of filters. In the scientific literature, several theoretical or empirical approaches are reported to describe the particle collection mechanisms. To this end, one of the challenges encountered by authors is to take into consideration the air flow pattern in the filter vicinity. Rebaï et al. $[1,2]$ combined a semi-analytical 1D flow model with an empirical clogging model to predict the pressure drop at high filtration velocity $\left(0.39-1.42 \mathrm{~m} \cdot \mathrm{s}^{-1}\right)$ representative of gas filtration in automotive applications. They validated their flow model by Computational Fluid Dynamics (CFD) calculations. Fotovati et al. [3,4] developed a macroscale model combining CFD flow calculation in laminar regime with a semi-empirical particle collection model to quantify the instantaneous pressure drop and total collection efficiency. Fotovati et al. [3] dealt with surface filtration regime by HEPA filters while Fotovati et al. [4] worked on depth filtration by pre-filters and validated their model by considering the flat filter configuration on the basis of the semi-empirical model developed by Thomas et al. [5]. This work was continued by Saleh et al. [6] who combined both algorithms into one simulation scheme to model the service life of pleated filters exposed to a polydisperse aerosol (1-10 $\mu \mathrm{m})$. However, they did not validate their model using experimental data. In order to reduce simulation times, Saleh and Tafreshi [7] developed a 2D semi-numerical model to predict both instantaneous pressure drop and total collection efficiency by using empirical expressions to describe the velocity field, as an alternative to CFD calculations. Saleh et al. [8] complemented this work by developing a novel set of analytical expressions. In the last two papers, they compared their results with those obtained with their more realistic CFD flow calculations, and with the experimental data of Gervais et al. [9] obtained with HEPA filters. Their conclusions were that their approaches could predict the service life of pleated filters at the early stages of a design process, but became less accurate near the clogging stage.

The literature thus exhibits several approaches dealing with particle clogging modeling in pleated filters. As they involve various flow conditions, filter types (and thus properties), and particle size distributions, it is difficult to draw general conclusions about the design optimization of pleated filters. From the different studies dealing with this issue, it appears that the parameter that is generally taken into consideration is the pressure drop under clean conditions $[10,13]$ as this is responsible for the filter energy consumption. However, depending on its geometrical properties, the air flow pattern in the vicinity of the filter may exhibit significant local variations, which could impact particle distribution on the media surface area and, consequently, the filtration efficiency. To deal with this issue, CFD is the most relevant tool.

There are several studies in the literature reporting numerical simulations of air flow in the vicinity of pleated filters. As they cover a wide range of media and filter properties as well as flow conditions, the main information about the conditions that were tested in these studies are detailed in Table 1 . In this table, $\mathrm{Z}, \mathrm{B}$ and $\varepsilon$ are the media thickness, permeability and porosity, respectively, $D_{\mathrm{f}}$ is the fiber mean diameter, and $\mathrm{H}$ and $\mathrm{W}$ are the pleat height and width. Pleated filters can be represented by rectangular or triangular shapes. Most authors consider their media isotropic and use a mean permeability value $B$. To model the permeability of different media (HEPA and pre-filters), Fotovati et al. $[3,4]$ used the expressions of Spielman and Goren [14] to calculate the in-plane permeability $\mathrm{B}_{\mathrm{IP}}$ and the through-plane permeability $\mathrm{B}_{\mathrm{TP}}$ components.

These studies mostly involve one or a half pleat through 2D computational domains. Tronville and Sala [12] compared the results obtained with three pleats within a 3D domain to those of a half pleat in a 2D domain and reported good agreement between them.

Concerning flow conditions, the authors generally specify the

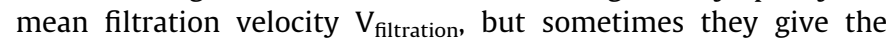
mean inlet duct velocity $V_{\text {inlet }}$. Due to the operating conditions of pleated filters, most numerical studies involve laminar flow to represent the flow field within them. Cases requiring flow simulation in the turbulent regime raise the issue of turbulence model selection. Tronville and Sala [12] and Feng et al. [15] reported some data that enabled a comparison of the ability of different turbulence models to predict the pressure drop and the velocity profiles of pleated filters.

\section{Material and methods}

\subsection{Overall methodology}

The combined numerical and experimental investigations involved in this study to predict the filtration performance of 
Table 1

Studies of the literature dealing with numerical simulations of air flow through pleated filters.

\begin{tabular}{|c|c|c|c|c|}
\hline Authors & Media type and properties & $\begin{array}{l}\text { Filter type and geometrical } \\
\text { properties }\end{array}$ & $\begin{array}{l}\text { Flow regime/model and velocity range } \\
\left(\mathrm{m} \mathrm{s}^{-1}\right)\end{array}$ & $\begin{array}{l}\text { Simulation } \\
\text { domain }\end{array}$ \\
\hline $\begin{array}{l}\text { Fotovati } \\
\text { et al. [4] }\end{array}$ & $\begin{array}{l}-Z=0.7 \mathrm{~mm} \\
-B_{I P}=5.028 \cdot 10^{-10} \mathrm{~m}^{2} \text { and } B_{T P}=3.117 \cdot 10^{-10} \mathrm{~m}^{2} \\
-\varepsilon=0.95 \\
-D_{f}=15 \mu \mathrm{m}\end{array}$ & $\begin{array}{l}\text { Pleated filters, triangular } \\
\text { shaped: } \\
-\mathrm{H}=25.4 \mathrm{~mm} \\
-\mathrm{W}=2.1-6.4 \mathrm{~mm}\end{array}$ & $\begin{array}{l}\text { - Laminar flow } \\
\text { - Vinlet }=0.05-0.5 \mathrm{~m} \mathrm{~s}^{-1}\end{array}$ & $\begin{array}{l}-2 \mathrm{D} \\
-1 / 2 \text { pleat }\end{array}$ \\
\hline $\begin{array}{l}\text { Fotovati } \\
\text { et al. [3] }\end{array}$ & $\begin{array}{l}\text { HEPA media } \\
\begin{array}{l}-\mathrm{Z}=0.38 \mathrm{~mm} \\
-\varepsilon=0.90-0.96 \\
-\mathrm{Df}=6-15 \mu \mathrm{m} \\
-3 \quad \text { anisotropic media: } \mathrm{B}_{\mathrm{IP}}=6.92 \cdot 10^{-10}-2.78 \\
\quad 10^{-11} \mathrm{~m}^{2} \text { and } \mathrm{B}_{\mathrm{TP}}=4.40 \cdot 10^{-10}-1.51 \cdot 10^{-11} \mathrm{~m}^{2} \\
-3 \text { isotropic media: } \mathrm{B}=5.58 \cdot 10^{-10}-2.25 \cdot 10^{-11} \mathrm{~m}^{2}\end{array}\end{array}$ & $\begin{array}{l}\text { Pleated filters, rectangular } \\
\text { shaped, triangular shaped: } \\
-\mathrm{H}=25.4 \mathrm{~mm} \\
-\mathrm{W}=1.3-8.5 \mathrm{~mm}\end{array}$ & $\begin{array}{l}\text { - Laminar flow } \\
\text { - Vinlet }=0.2-1.0 \mathrm{~m} \mathrm{~s}^{-1}\end{array}$ & $\begin{array}{l}-2 \mathrm{D} \\
-1 \text { pleat }\end{array}$ \\
\hline $\begin{array}{l}\text { Rebaï et al. } \\
\text { [1] }\end{array}$ & $\begin{array}{l}\text { Synthetic fibrous media: } \\
\qquad \begin{array}{l}-Z=1.45 \mathrm{~mm} \\
-\mathrm{B}=3.565 \cdot 10^{-10} \mathrm{~m}^{2}\end{array}\end{array}$ & $\begin{array}{l}\text { Pleated filter, rectangular } \\
\text { shaped, triangular shaped: } \\
\quad-\mathrm{H}=51 \mathrm{~mm} \\
-\mathrm{W}=12.5 \mathrm{~mm}\end{array}$ & $\begin{array}{l}\text { - Laminar flow } \\
\text { - Vfiltration }=0.39 \mathrm{~m} \mathrm{~s}^{-1}\end{array}$ & \\
\hline $\begin{array}{l}\text { Del Fabbro } \\
\text { et al. [11] }\end{array}$ & $\begin{array}{l}\text { Low Efficiency media (cellulose fiber): } \\
-\mathrm{B}=3.80 \cdot 10^{-11} \mathrm{~m}^{2} \\
-\varepsilon=0.88\end{array}$ & $\begin{array}{l}\text { Pleated filters, rectangular } \\
\text { shaped, triangular shaped: } \\
-\mathrm{H}=27-48 \mathrm{~mm} \\
-\mathrm{W}=2.0-3.5 \mathrm{~mm}\end{array}$ & $\begin{array}{l}\text { - Laminar flow } \\
-\mathrm{V}_{\text {filtration }}=0.07 \mathrm{~m} \mathrm{~s}^{-1}\end{array}$ & $\begin{array}{l}-2 \mathrm{D} \\
-1 / 2 \text { pleat }\end{array}$ \\
\hline $\begin{array}{l}\text { Tronville } \\
\text { and Sala } \\
\text { [12] }\end{array}$ & $\begin{array}{l}-Z=0.38 \mathrm{~mm} \\
-B=7.5 \cdot 10^{-12} \mathrm{~m}^{2}\end{array}$ & $\begin{array}{l}\text { Mini pleated filter, triangular } \\
\text { shaped: } \\
\quad-\mathrm{H}=25 \mathrm{~mm} \\
-\mathrm{W}=3.2 \mathrm{~mm}\end{array}$ & $\begin{array}{l}\text { - Turbulence models: rsm, Standard } \\
\text { k- }-\varepsilon \text {, RNG k- } \varepsilon \\
-\mathrm{V}_{\text {inlet }}=0.5-2.0 \mathrm{~m} \mathrm{~s}^{-1}\end{array}$ & $\begin{array}{l}-3 \mathrm{D} \text { and } 2 \mathrm{D} \\
-3 \text { pleats } \\
\text { and } 1 / 2 \\
\text { pleat }\end{array}$ \\
\hline $\begin{array}{l}\text { Del Fabbro } \\
\text { et al. [11] }\end{array}$ & $\begin{array}{l}\text { HEPA media (glass fiber): } \\
-\mathrm{B}=1.19 \cdot 10^{-12} \mathrm{~m}^{2} \\
-\varepsilon=0.92\end{array}$ & $\begin{array}{l}\text { Pleated filters, rectangular } \\
\text { shaped, triangular shaped: } \\
-\mathrm{H}=27-48 \mathrm{~mm} \\
-\mathrm{W}=2.0-3.5 \mathrm{~mm}\end{array}$ & $\begin{array}{l}\text { - Laminar flow } \\
-\mathrm{V}_{\text {filtration }}=0.07 \mathrm{~m} \mathrm{~s}^{-1}\end{array}$ & $\begin{array}{l}-2 \mathrm{D} \\
-1 / 2 \text { pleat }\end{array}$ \\
\hline $\begin{array}{l}\text { Chen et al. } \\
\text { [10] }\end{array}$ & $\begin{array}{l}-Z=0.38 \mathrm{~mm} \\
-B=1.1 \cdot 10^{-11}-7.52 \cdot 10^{-13} \mathrm{~m}^{2}\end{array}$ & $\begin{array}{l}\text { Mini pleated, rectangular } \\
\text { shaped: } \\
\quad-\mathrm{H}=22.22-133.25 \mathrm{~mm} \\
-\mathrm{W}=1.27-8.47 \mathrm{~mm}\end{array}$ & $\begin{array}{l}\text { - Laminar flow } \\
-\mathrm{V}_{\text {filtration }}=0.13-1.3 \mathrm{~m} \mathrm{~s}^{-1}\end{array}$ & $\begin{array}{l}-2 \mathrm{D} \\
-1 / 2 \text { pleat }\end{array}$ \\
\hline $\begin{array}{l}\text { Feng et al. } \\
\text { [15] }\end{array}$ & $\begin{array}{l}\text { Polypropylene media: } \\
-\mathrm{Z}=0.30 \mathrm{~mm} \\
-\mathrm{B}=8.33 \cdot 10^{-13} \mathrm{~m}^{2}\end{array}$ & $\begin{array}{l}\text { Pleated filter, rectangular } \\
\text { shaped: } \\
\quad-\mathrm{H}=50 \mathrm{~mm} \\
-\mathrm{W}=50 \mathrm{~mm}\end{array}$ & $\begin{array}{l}\text { - Turbulence model: LES (SGS), DES } \\
\text { (SA), LRN k- }-\varepsilon \text {, Standard } \mathrm{k}-\varepsilon \text {, v2f } \\
-\mathrm{V}_{\text {inlet }}=0.13 \mathrm{~m} \mathrm{~s}^{-1} \\
-\mathrm{V}_{\text {filtration }}=0.072 \mathrm{~m} \mathrm{~s}^{-1}\end{array}$ & $\begin{array}{l}-2 \mathrm{D} \\
-1 / 2 \text { pleat }\end{array}$ \\
\hline
\end{tabular}

pleated fibrous filters were performed with a coarse filter used in various geometrical configurations. The filter has a permeability of $10^{-9} \mathrm{~m}^{2}$ order of magnitude. Such a high permeability value, combined with the pleat width range tested $(11.5-23.0 \mathrm{~mm})$ enables to broaden the pleated filter properties numerically studied compared to the cases reported in the literature (cf. Table 1). The coarse filter was also chosen as it is widely used in multistage configurations.

The first step of the study consisted in characterizing the structural parameters of the fibrous media and its permeability in order to use the Darcy-Forchheimer equation in the Fluent CFD code to predict the pressure drop through the unused media in flat configuration. The second step consisted in predicting the pressure drop of pleated filters from two-dimensional simulations. In order to validate the calculations, the pressure drop of three filters with various pleat widths and heights was measured.

\subsection{Experimental conditions}

The media studied is of G4 type according to the European standard EN779-2012, and is made of cotton and polyester fibers. Its main structural properties were characterized and average values were calculated from 3 measurements. The thickness of the media, measured with a micrometer, is $2.8 \pm 0.7 \mathrm{~mm}$. The mean fiber diameter, determined from SEM (JEOL 5800-LV) picture analysis, is $13.8 \pm 4.4 \mu \mathrm{m}$ (70 fibers observed). The porosity of the media, determined by mercury porosimetry (Micromeritics Autoport IV), is $0.92 \pm 0.01$. Its weight, determined by weighing dried samples with known surface areas, is $65 \pm 5 \mathrm{~g} \cdot \mathrm{m}^{-2}$.

Downsized pleated filters (with external dimensions of $120 \times 120 \mathrm{~mm}^{2}$ ) with three different geometrical configurations were designed in the laboratory with this media. Their characteristics are given in Table 2. For each geometrical configuration, pressure drop measurements were carried out on at least 3 filters. The filter is commercialized by Camfil with the geometrical configuration of the prototype P1 (cf. Fig. 1) whose nominal filtration velocity is $0.8 \mathrm{~m} \cdot \mathrm{s}^{-1}$.

Concerning the pleat width, the theoretical values $\mathrm{W}_{\mathrm{t}}$ as well as the average measured values $W_{m}$ are detailed in Table 2 . The measured values are the average width values, which were measured after laboratory manufacture of the downsized filters. The dimensions of the prototypes P2 and P3 were chosen in order to evaluate the influence of the pleat width (P1 versus $\mathrm{P} 3$ ) and height (P2 versus P3) on filter pressure drop. The developed surface area and pleat opening angle of prototypes P1 and P2 are similar. The developed surface area of the prototype P3 is around twice that of P1 and $\mathrm{P} 2$ whereas its opening angle is half that of prototypes P1 and P2. The theoretical width value is based on that of the commercial filter for the P1 geometry and is thus half this value for the $\mathrm{P} 2$ and $\mathrm{P} 3$ configurations.

The downsized filters were tested in a lab-scale air handling unit (AHU) enabling pressure drop measurements in controlled 
Table 2

Geometrical properties of the prototypes tested.

\begin{tabular}{|c|c|c|c|c|c|}
\hline Geometry & Pleat height $\mathrm{H}(\mathrm{mm})$ & Pleat width $\mathrm{W}_{\mathrm{t}}(\mathrm{mm})$ theoretical & Pleat width $\mathrm{W}_{\mathrm{m}}(\mathrm{mm})$ measured & Pleat opening angle & Pleat number \\
\hline P1 & 40 & 23.0 & 19.8 & $\alpha$ & 6 \\
\hline $\mathrm{P} 2$ & 20 & 11.5 & 11.3 & $\alpha$ & 12 \\
\hline P3 & 40 & 11.5 & 10.2 & $\alpha / 2$ & 12 \\
\hline
\end{tabular}

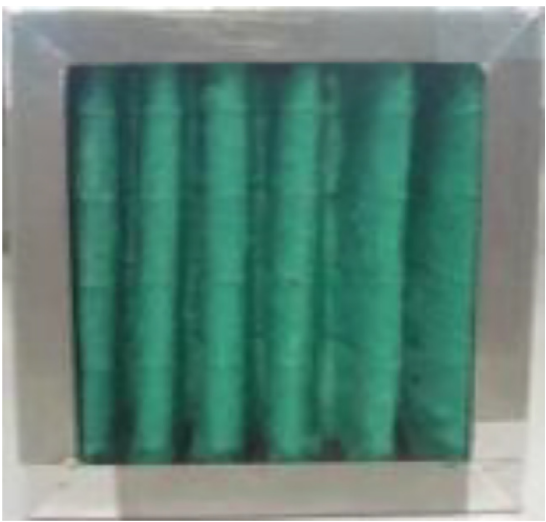

Fig. 1. Picture of the P1 prototype.

temperature and relative humidity conditions [16]. The pressure drop was determined from the differential pressure measurement between upstream and downstream of the filter.

\subsection{Numerical conditions}

\subsubsection{Computational domain and boundary conditions}

For the numerical simulations, domains consisting of twodimensional meshes were generated to simulate the flow through half-pleats. Three meshes were used to study the flow in the vicinity of the three pleat geometries investigated experimentally. In each mesh the half-pleat was positioned after a straight length of $180 \mathrm{~mm}$, inside a total length of $455 \mathrm{~mm}$. In order to compare experimental and numerical pressure drop of unused filters as a function of the mean filtration velocity (cf. Section 4.2), the calculations were carried out with a pleat width corresponding to the measured values $\mathrm{W}_{\mathrm{m}}$. For those calculations the cell numbers were 86,500; 50,054 and 54,124 for the prototypes P1; P2 and P3 respectively. To analyze the air flow pattern in the filter vicinity (Sections 4.3 and 4.4) thanks to CFD results, the theoretical pleat width $\mathrm{W}_{\mathrm{t}}$ was considered. For those calculations the cell numbers were 97,358; 50,054 and 58,464 for the prototypes P1; P2 and P3 respectively. The meshes were structured in the two empty straight lengths upstream and downstream of the filter and inside the media, and unstructured in the two zones in the close filter vicinity. The minimum cell size was defined for the media thickness, and was of $0.1 \mathrm{~mm}$. Additional simulations were carried out with refined meshes in the filter vicinity and led to similar results, so the previously cited meshes were retained.

The boundary conditions used are presented in Fig. 2. The halfpleats were inserted between two symmetry conditions. A constant velocity inlet value was imposed at the domain inlet. At the domain outlet, a pressure outlet of 101,325 Pa was fixed.

\subsubsection{CFD models and equations}

The governing equations for the air flow were the Navier-Stokes equations, which were solved at steady-state. The model used by the Ansys Fluent code to predict the pressure drop generated by porous media is the Darcy Forchheimer equation (Eq. (1)), which takes into account the viscous as well as the inertial resistances to the flow:

$\frac{\Delta P}{Z}=\frac{\mu}{B} \cdot V+\frac{C}{2} \cdot \rho \cdot V^{2}$

where $\mu$ and $\rho$ are the air dynamic viscosity and density, $\mathrm{V}$ is the air velocity, $B$ is the media permeability and $C$ is the inertial resistance coefficient. B and C were considered isotropic.

Due to the air velocity range covered in the AHU $\left(0.6-5.6 \mathrm{~m} \cdot \mathrm{s}^{-1}\right)$, and the corresponding Reynolds range $(1550-45,000)$ the flow in the filter vicinity was considered turbulent. Two turbulence models were studied and compared: the standard k-epsilon model $(\mathrm{k}-\varepsilon)$ and the Reynolds stress model ( $\mathrm{rsm})$. Due to the filtration velocity range corresponding to this air velocity range: from 0.09 to $0.81 \mathrm{~m} \cdot \mathrm{s}^{-1}$, the flow in the porous media was considered linear laminar (and thus only the viscous resistance was taken into consideration).

\section{Results and discussion}

\subsection{Determination of the fibrous media permeability and inertial resistance}

In order to determine the media permeability $\mathrm{B}$ and inertial resistance $C$, pressure drop $\Delta P$ measurements of the fibrous filter in flat configuration were carried out in the lab-scale AHU for an air velocity ranging from 0.1 to $2.0 \mathrm{~m} \cdot \mathrm{s}^{-1}$. The experimental data are presented in Fig. 3; they represent the average values from three different samples of media and error bars indicate max and min values. The results reveal a wide dispersion of the pressure drop with increasing air velocity, which indicates a significant heterogeneity of the media.

These experimental data were modeled through the Darcy-Forchheimer equation (Eq. (1)). The permeability was derived from the linear part of the curve (linear laminar flow regime) which corresponds to an air velocity of $0.1-0.5 \mathrm{~m} \cdot \mathrm{s}^{-1}$. The calculated values of $B$ and $C$ were $2.0 \pm 0.5 \cdot 10^{-9} \mathrm{~m}^{2}$ and $3344 \pm 1000 \mathrm{~m}^{-1}$, respectively.

\subsection{Influence of the filter geometrical properties on the pressure drop}

Fig. 4 represents the numerical and experimental change in the filter pressure drop versus the mean filtration velocity. The numerical simulations involve pleat widths equal to the mean values of the experimental prototypes.

First, the experimental results reveal a significant influence of the pleat geometrical parameters on the change in pressure drop in accordance with the results of Del Fabbro et al. [11] and Rebai et al. [1] for different filter properties and flow conditions. For a given pleat height, the pressure drop decreases as the pleat width increases (P1: $\mathrm{H} 40 \mathrm{~W}_{\mathrm{m}} 20$ and $\mathrm{P} 3$ : $\mathrm{H}_{40} \mathrm{~W}_{\mathrm{m}}$ 10). For a given pleat width, the pressure drop decreases as the pleat height decreases (P2: $\mathrm{H} 20 \mathrm{~W}_{\mathrm{m}} 11$ and $\mathrm{P} 3: \mathrm{H} 40 \mathrm{~W}_{\mathrm{m}} 10$ ). Thus, in the range of pleat heights and widths tested, the pressure is lowered by a large width and small height of the pleats. Moreover, the influence of the geometrical parameters on the pressure drop is more significant with increasing air filtration velocity. 


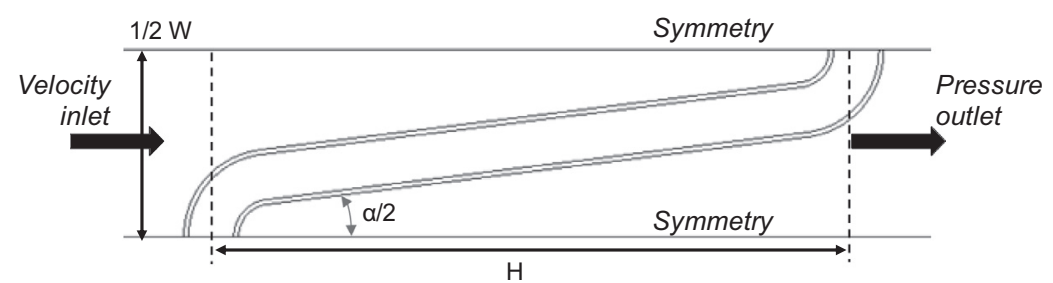

Fig. 2. Diagram of the simulation domain and the boundary conditions used.

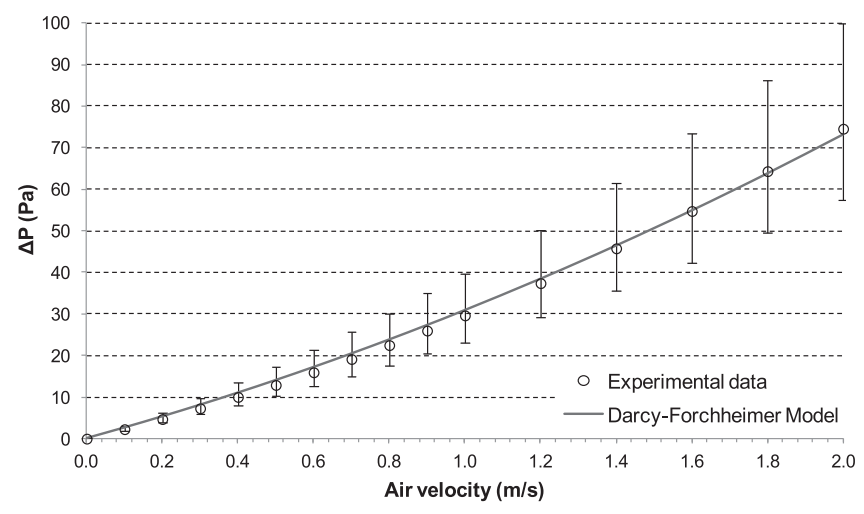

Fig. 3. Comparison between measured and modeled (by the Darcy-Forchheimer equation) pressure drop versus air velocity for the flat configuration of the filter tested.

Secondly, the results indicate that the numerical simulations fit well with the experimental data. Thus, for the media used, the standard $\mathrm{k}-\varepsilon$ turbulence model and an isotropic permeability enable an accurate prediction of the filter pressure drop. The same results were obtained when using the rsm model for the P1 prototype.

Feng et al. [15] showed that the standard k- $\varepsilon$ turbulence model accurately predicted the experimental pressure drop of filters with a low permeability of $8.33 \cdot 10^{-12} \mathrm{~m}^{2}$. However, they also demonstrated that for the filter tested by Rebaï et al. [1], whose permeability was $3.57 \cdot 10^{-10} \mathrm{~m}^{2}$, the standard $\mathrm{k}-\varepsilon$ turbulence model (as well as the Low Reynolds Number $\mathrm{k}-\varepsilon$ model) failed to predict the pressure drop (which was successfully predicted by the Large Eddy Simulation, the v2f model; i.e. a model close to the standard $\mathrm{k}-\varepsilon$ developed for a low velocity and wall bounded flow, and the
Detached Eddy Simulation models). Tronville and Sala [12] compared the pressure drop obtained for three different turbulence models to those measured experimentally for their mini-pleated filters (with a low permeability of $7.5 \cdot 10^{-12} \mathrm{~m}^{2}$ ) and highlighted that, contrary to the standard $\mathrm{k}-\varepsilon$ turbulence model, the rsm model described the experimental pressure drop better.

These results show that for each configuration (media type, filter geometrical properties, mean filtration velocity range), the selection of the turbulence model must be well addressed. Moreover, special care must be taken in defining the geometry of pleats as the wrong specification of their height and width could lead to significant variations in their pressure drop.

To highlight this issue, Fig. 5 studies the sensitivity of the simulated filter pressure drop to the pleat width. For this purpose, the pressure drop obtained for the P3 filter with a mean measured width is compared to that obtained with the theoretical width. The results show that an $11 \%$ deviation in pleat width leads to significant pressure drop deviations: a $21 \%$ discrepancy is reached at the highest simulated mean filtration velocity $\left(0.69 \mathrm{~m} \cdot \mathrm{s}^{-1}\right)$.

In general it is also possible that the pleating operation involved in filters manufacture induces some compression effect on the media that could slightly modify the pleats dimensions.

\subsection{Influence of the turbulence model on velocity profiles in the pleat} vicinity

In the present study, two different turbulence models were tested to model the air flow in the vicinity of the filter for the prototype P1: the standard $\mathrm{k}-\varepsilon$ and the Reynolds stress model (suggested by Tronville and Sala [12]). The pressure drop obtained with the two models were similar (cf. Section 4.2), suggesting no influence of the turbulence model on the pressure drop prediction in the mean filtration velocity range tested $\left(0.14-0.79 \mathrm{~m} \cdot \mathrm{s}^{-1}\right)$. The

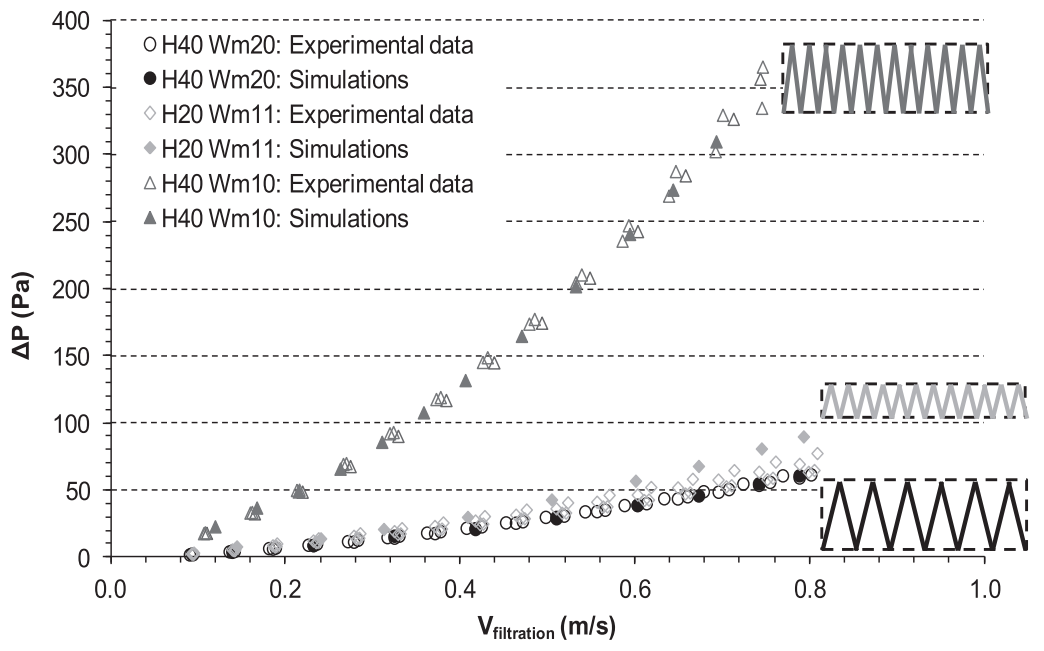

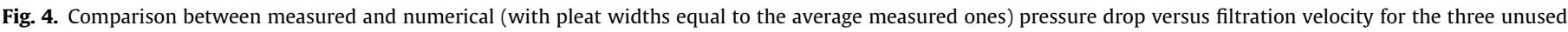
filter prototypes: $\mathrm{H} 40 \mathrm{~W}_{\mathrm{m}} 20=\mathrm{P} 1, \mathrm{H} 20 \mathrm{~W}_{\mathrm{m}} 11=\mathrm{P} 2, \mathrm{H} 40 \mathrm{~W}_{\mathrm{m}} 10=\mathrm{P} 3$. 


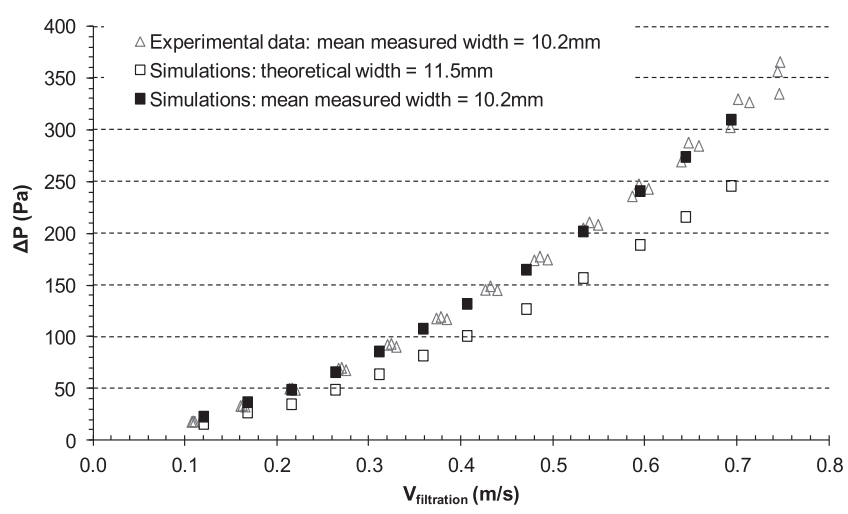

Fig. 5. Sensitivity of the simulated pressure drop to the pleat width for the unused prototype P3 of the filter: theoretical width: $\mathrm{H} 40 \mathrm{~W}_{\mathrm{t}} 12$, mean measured width: $\mathrm{H} 40$ $\mathrm{W}_{\mathrm{m}} 10$.

subject of this section is the influence of the turbulence model on velocity profiles in the pleat vicinity for the prototype P1.

In order to present the longitudinal velocity profiles upstream and downstream of the filter, the representation illustrated in Fig. 6 was adopted. The vertical coordinate Y was defined in the same way upstream and downstream of the media through the dimensionless coordinate $\mathrm{Y} / \mathrm{Y}_{0}, \mathrm{Y}_{0}$ being defined as the distance between the media surface and the computational domain limit (symmetry axis) for each coordinate $\mathrm{X}$. Thus the $\mathrm{Y} / \mathrm{Y}_{0}$ ratio is equal to 0 at the media surface, and to 1 at the computational domain limit (symmetry boundary conditions).

The velocity profiles upstream and downstream of the filter obtained from the two tested models for a mean filtration velocity of $0.7 \mathrm{~m} \cdot \mathrm{s}^{-1}$, close to the nominal filtration velocity of the commercial filter $\left(0.8 \mathrm{~m} \cdot \mathrm{s}^{-1}\right)$, are presented in Figs. 7 and 8 , respectively. It appears that more deviations between the velocity profiles obtained with the two models occur downstream of the filter (Fig. 8). The velocity profiles upstream of the filter (Fig. 7), which are of primary interest to evaluate the particle collection by fibers, are not significantly influenced by the turbulence model, except in the close vicinity of the filter (for a $\mathrm{Y} / \mathrm{Y}_{0}$ ratio close to zero) where maximum deviations are about $10 \%$. Thus, the widespread $\mathrm{k}-\varepsilon$ model was selected for the simulations performed for the other two prototypes.

Turbulence model selection would require local velocity measurements, especially downstream of the filter where the most significant deviations are observed. The only study addressing this issue is the recent one of Feng et al. [15]. They measured the onedimensional velocity component ( $\mathrm{x}$-velocity component) downstream of the filter along the $\mathrm{X}$ and $\mathrm{Y}$ directions using hot wire anemometry. Their results show that the ability of a turbulence model to predict velocity patterns accurately varies significantly with the filter and media properties, and with the flow conditions.
4.4. Influence of the filter geometrical properties on velocity profiles in the pleat vicinity

The velocity profiles for the three geometrical configurations were compared for a similar mean filtration velocity of $0.7 \mathrm{~m} \cdot \mathrm{s}^{-1}$, close to the nominal filtration velocity of the commercial filter tested $\left(0.8 \mathrm{~m} \cdot \mathrm{s}^{-1}\right)$.

The velocity profiles upstream of the filter, at different axial $\mathrm{X}$ coordinates along the pleat, for the prototype $\mathrm{P} 1$ are presented in Fig. 9. Almost all of these profiles highlight that from about 0.2 normalized distance to the media $\mathrm{Y} / \mathrm{Y}_{0}$ the velocity is rather uniform. The most significant velocity gradient is thus located in the vicinity of the media surface (from the surface, i.e. $\mathrm{Y} / \mathrm{Y}_{0}=0$, to $20 \%$ of the distance between the surface and the symmetry axis, i.e. $\mathrm{Y} / \mathrm{Y}_{0}=0.2$ ). These penetration profiles are similar to those reported by Rebaï et al. [1]. Moreover, far from the filter surface (from $\mathrm{Y} / \mathrm{Y}_{0}=0.2$ to 1.0 ), the air velocity does not depend significantly on the axial coordinate (for $\mathrm{X}=4$ to $31 \mathrm{~mm}$ ), except at the pleat entrance (from $X=0$ to $4 \mathrm{~mm}$ ) and in the pleat bottom (from $\mathrm{X}=32$ to $36 \mathrm{~mm}$ ).

Fig. 10 compares the velocity profiles upstream of the filter for the three geometrical configurations at the mean filtration velocity of $0.7 \mathrm{~m} \cdot \mathrm{s}^{-1}$ (calculated with the theoretical pleat width) at three axial coordinates along the pleat: at the pleat entrance $(x=4 \mathrm{~mm}$ for the prototypes $\mathrm{P} 1$ and $\mathrm{P} 3$ and $\mathrm{x}=2 \mathrm{~mm}$ for the prototype P2), at the half pleat height $(\mathrm{x}=20 \mathrm{~mm}$ for the prototypes $\mathrm{P} 1$ and $\mathrm{P} 3$ and $\mathrm{x}=10 \mathrm{~mm}$ for the prototype $\mathrm{P} 2$ ), and the pleat bottom depth $(\mathrm{x}=36 \mathrm{~mm}$ for the prototypes $\mathrm{P} 1$ and $\mathrm{P} 3$ and $\mathrm{x}=18 \mathrm{~mm}$ for the prototype $\mathrm{P} 2$ ). The comparison between the three prototypes shows that the more pleated the media is (tight pleats, with low opening angle) and the higher the pleats are, the more significant the velocity gradient is. In fact, for the prototype P3 $\left(\mathrm{H} 40 \mathrm{~W}_{\mathrm{t}} 11\right)$ the velocity ranges from around $2 \mathrm{~m} \cdot \mathrm{s}^{-1}$ at the air/media interface $\left(\mathrm{Y} / \mathrm{Y}_{0}=0\right)$ in the pleat entrance zone $(\mathrm{x}=4 \mathrm{~mm})$ to around $16 \mathrm{~m} \cdot \mathrm{s}^{-1}$ when reaching the symmetry axis in the deep pleat bottom zone $(x=20$ and $36 \mathrm{~mm}$ ), whereas the velocity ranges observed for the prototypes $\mathrm{P} 1\left(\mathrm{H} 40 \mathrm{~W}_{\mathrm{t}} 23\right)$ and $\mathrm{P} 2\left(\mathrm{H} 20 \mathrm{~W}_{\mathrm{t}} 11\right)$ are $1-5 \mathrm{~m} \cdot \mathrm{s}^{-1}$ and $1-7 \mathrm{~m} \cdot \mathrm{s}^{-1}$, respectively.

In order to have orders of magnitude of local velocities at which particles would reach the filter, the evolutions of the velocity at the air/filter interface along the pleat are compared in Fig. 11 for the three configurations for the mean filtration velocity of $0.7 \mathrm{~m} \cdot \mathrm{s}^{-1}$. This figure shows that the velocity at the filter interface exhibits a minimum at $\mathrm{x}=4 \mathrm{~mm}$ for the prototypes $\mathrm{P} 1$ (of $1 \mathrm{~m} \cdot \mathrm{s}^{-1}$ ) and P3 (of $2 \mathrm{~m} \cdot \mathrm{s}^{-1}$ ) and at $\mathrm{x}=2 \mathrm{~mm}$ for the prototype P2 (of $1 \mathrm{~m} \cdot \mathrm{s}^{-1}$ ) which corresponds to the end of the bend. As mentioned by Rebai et al. [1], the curved region of the pleat must be considered carefully as the pleat manufacturing process may involve local compression of the media that could lead to local deviations in terms of thickness and permeability. Then, the velocity slightly increases up to $2.5 \mathrm{~m} \cdot \mathrm{s}^{-1}$ for the prototype P1 whereas it rises more significantly for the prototypes P2 (up to $4.1 \mathrm{~m} \cdot \mathrm{s}^{-1}$ ) and P3

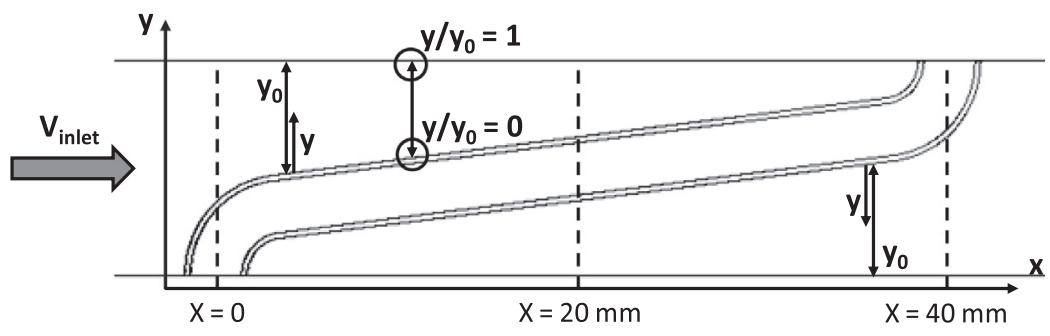

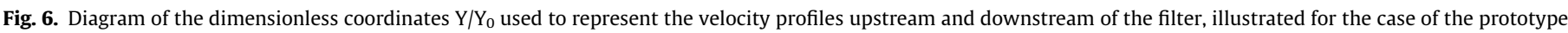
P1. 


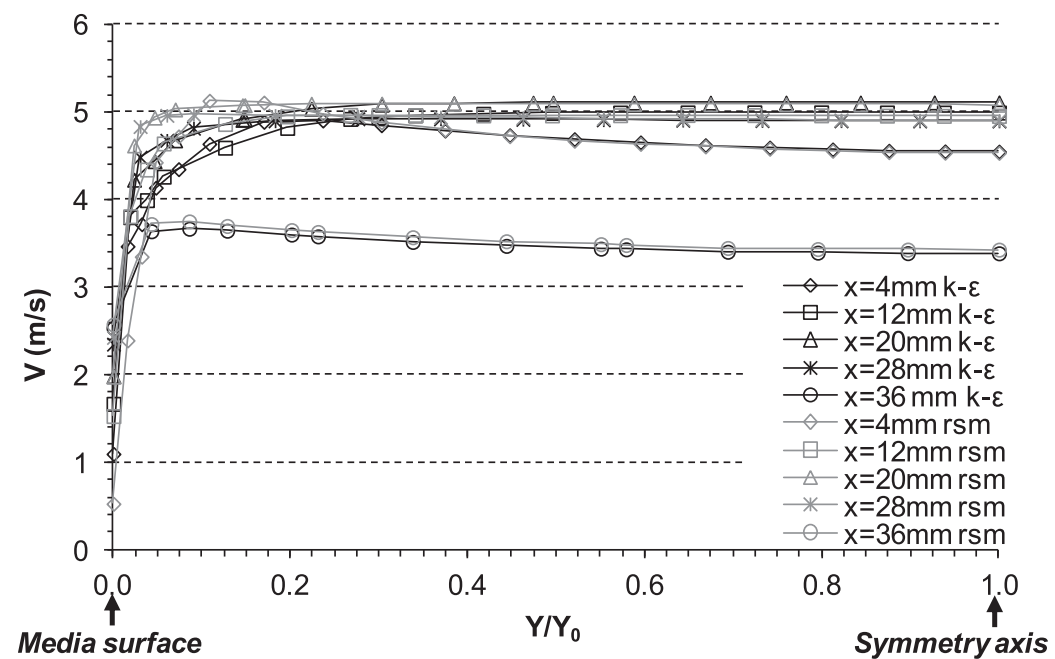

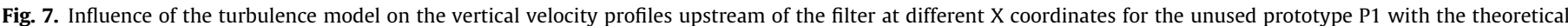
width: $\mathrm{H}_{40} \mathrm{~W}_{\mathrm{t}} 23$, at $\mathrm{V}_{\text {inlet }}=2.8 \mathrm{~m} \cdot \mathrm{s}^{-1}$ and $\mathrm{V}_{\text {filtration }}=7 \mathrm{~m} \cdot \mathrm{s}^{-1}$.

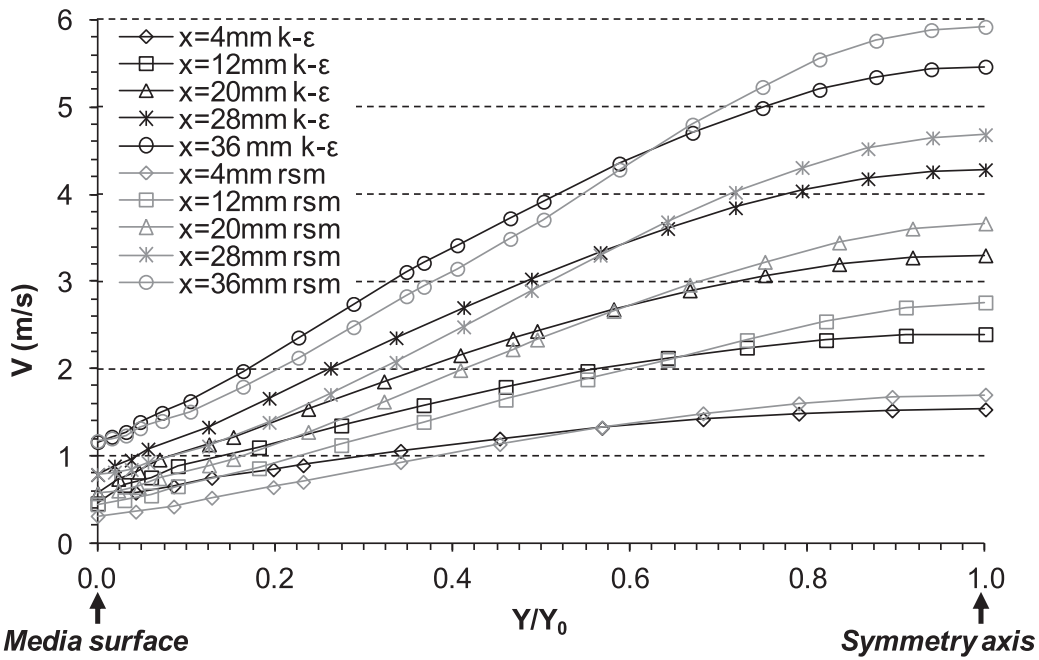

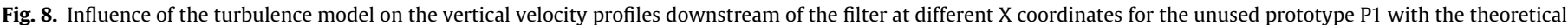
width: $\mathrm{H} 40 \mathrm{~W}_{\mathrm{t}} 23$, at $\mathrm{V}_{\text {inlet }}=2.8 \mathrm{~m} \cdot \mathrm{s}^{-1}$ and $\mathrm{V}_{\text {filtration }}=0.7 \mathrm{~m} \cdot \mathrm{s}^{-1}$.

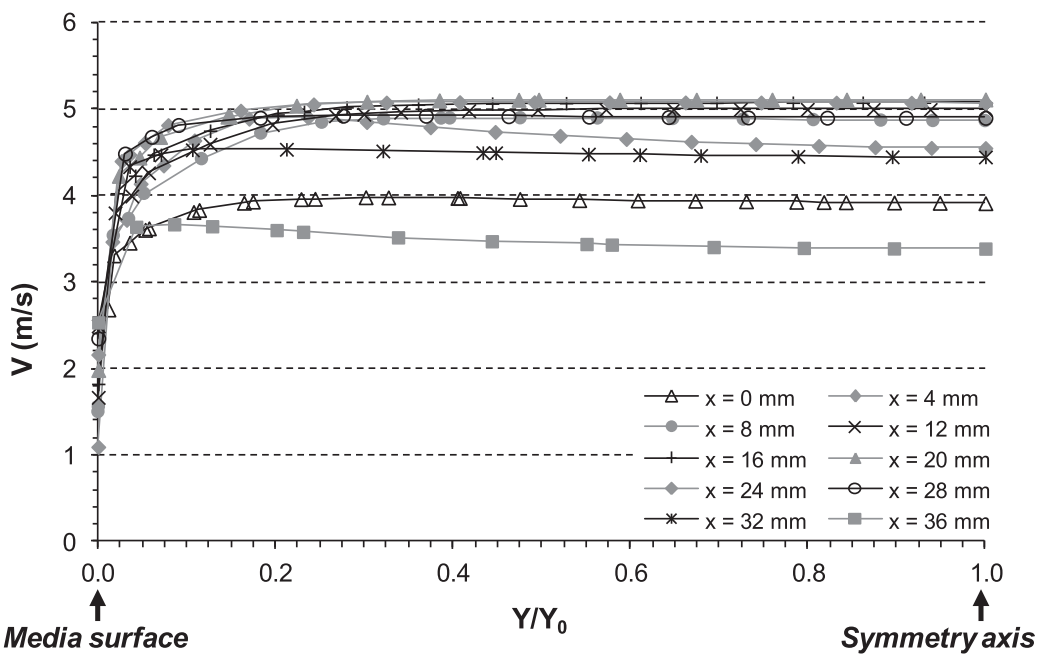

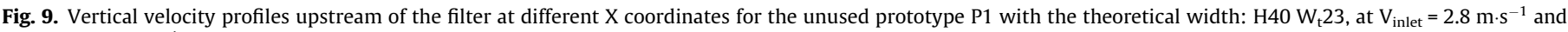
$\mathrm{V}_{\text {filtration }}=0.7 \mathrm{~m} \cdot \mathrm{s}^{-1}$. 


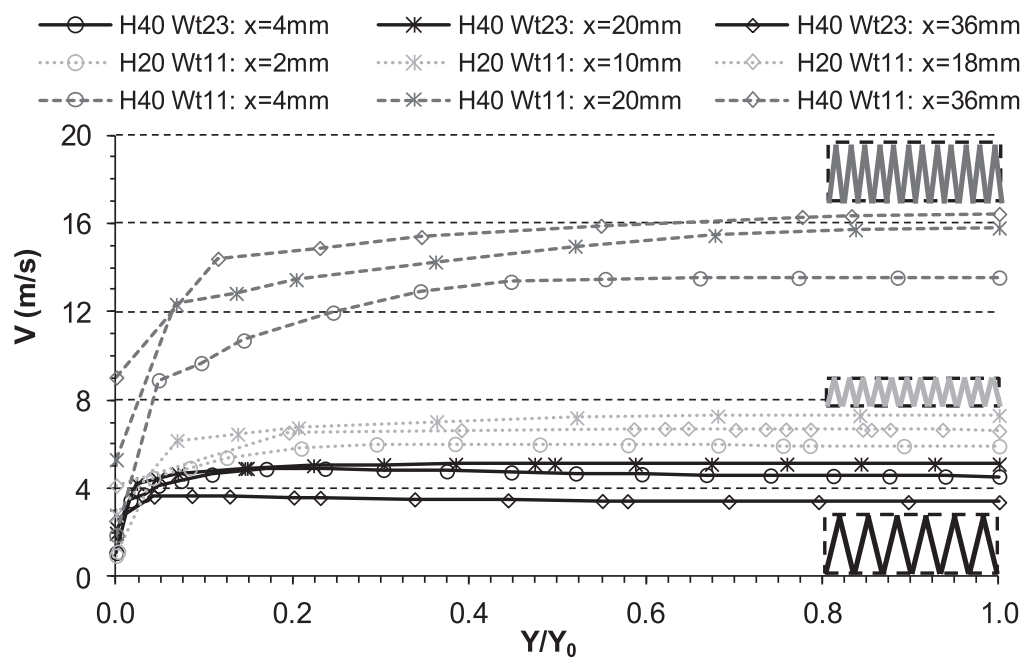

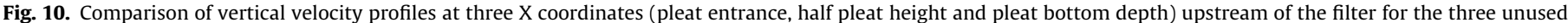
prototypes of the filter with theoretical pleat widths: $\mathrm{H} 40 \mathrm{~W}_{\mathrm{t}} 23=\mathrm{P} 1, \mathrm{H} 20 \mathrm{~W}_{\mathrm{t}} 11=\mathrm{P} 2, \mathrm{H} 40 \mathrm{~W}_{\mathrm{t}} 11=\mathrm{P} 3$ at $\mathrm{V}_{\text {filtration }}=0.7 \mathrm{~m} / \mathrm{s}$.

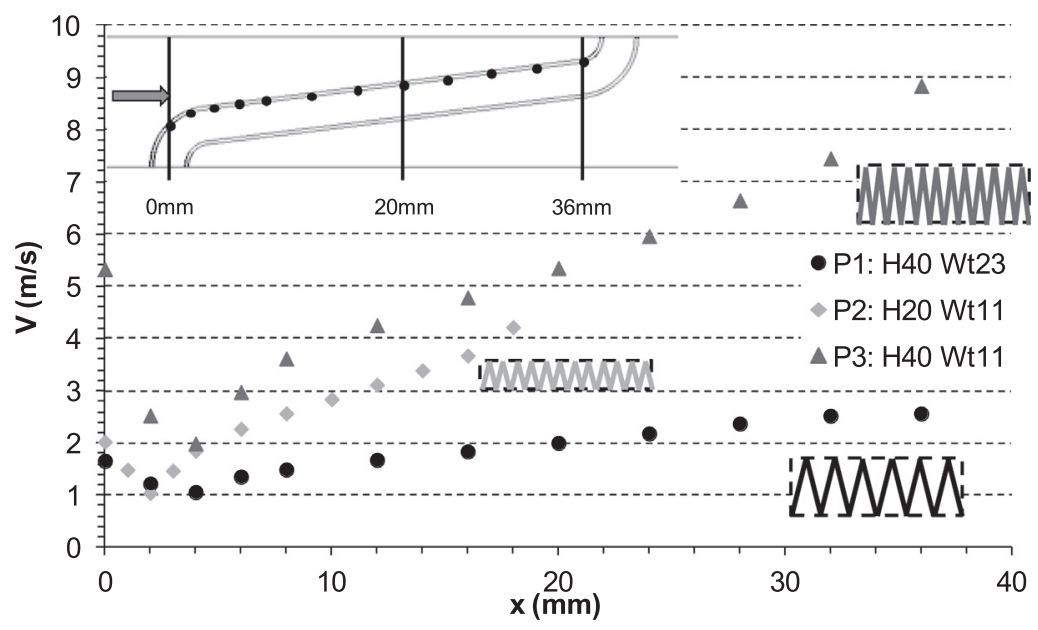

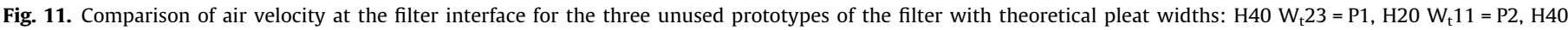
$\mathrm{W}_{\mathrm{t}} 11=\mathrm{P} 3$ at $\mathrm{V}_{\text {filtration }}=0.7 \mathrm{~m} / \mathrm{s}$.

(up to $9.0 \mathrm{~m} . \mathrm{s}^{-1}$ ) up to the pleat bottom depth. Thus, the magnitude of the velocity variations resulting from the pleat geometrical properties influences the velocity at the media interface. As these velocity variations are significant, the pleat shape used for CFD calculation must accurately reflect that of the experimental prototypes for proper comparisons.

\section{Conclusion}

The influence of the geometrical parameters of a coarse pleated fibrous filter on its pressure drop and velocity field was studied using experiments and numerical simulations. The filter properties simulated (in terms of media permeability and geometrical parameters) enable to extend the data reported in the literature. It was demonstrated that for such filter and for the filtration velocities tested both the $k-\varepsilon$ and rsm turbulence models enable an accurate prediction of the unused filter pressure drop. The pressure drop versus mean filtration velocity of unused filters enabled the numerical simulation conditions to be validated, and to point out that, in the range of pleat heights and widths tested, as expected, the pressure drop is lowered by a small pleat height and a large pleat width (toward a flat geometry).
The numerical velocity profiles in the pleat vicinity upstream of the filter, which are of primary interest regarding the particle collection by fibers, showed that tight and high pleats lead to the more significant velocity gradients, and to the higher velocity magnitude at the air/filter interface. On the contrary large and small pleats lead to the less significant velocity gradients and to the lower velocity magnitude at the air/filter interface. Those discrepancies should have an influence on the initial local collection efficiencies.

\section{References}

[1] M. Rebaï, M. Prat, M. Meireles, P. Schmitz, R. Baclet, A semi-analytical model for gas flow in pleated filters, Chem. Eng. Sci. 65 (9) (2010) 2835-2846.

[2] M. Rebaï, M. Prat, M. Meireles, P. Schmitz, R. Baclet, Clogging modeling in pleated filters for gas filtration, Chem. Eng. Res. Des. 88 (2010) 476-486.

[3] S. Fotovati, S.A. Hosseini, H. Vadehi Tafreshi, B. Pourdeyhimi, Modeling instantaneous pressure drop of pleated thin filter media during dust loading, Chem. Eng. Sci. 66 (2011) 4036-4046.

[4] S. Fotovati, H. Vadehi Tafreshi, B. Pourdeyhimi, A macroscale model for simulating pressure drop and collection efficiency of pleated filters over time, Chem. Eng. Sci. 98 (2012) 344-355.

[5] D. Thomas, P. Penicot, P. Contal, D. Leclerc, J. Vendel, Clogging of the fibrous filters by solid aerosol particles experimental and modeling study, Chem. Eng. Sci. 56 (11) (2001) 3549-3561. 
[6] A.M. Saleh, S. Fotovati, H. Vahedi Tafreshi, B. Pourdeyhimi, Modeling service life of pleated filters exposed to poly-dispersed aerosols, Powder Technol. 266 (2014) 79-89.

[7] A.M. Saleh, H. Vahedi Tafreshi, A simple semi-numerical model for designing pleated filters under dust loading, Sep. Purif. Technol. 137 (2014) 94-108.

[8] A.M. Saleh, S. Fotovati, H. Vahedi Tafreshi, B. Pourdeyhimi, An analytica approach to predict pressure drop and collection efficiency of dust-load pleated filters, Sep. Purif. Technol. 161 (2016) 80-87.

[9] P.C. Gervais, S. Poussier, N. Bardin-Monnier, G. Karcher, D. Thomas, Combination of single-photon emission and X-ray computed tomography to visualize aerosol deposition in pleated filter, Sep. Purif. Technol. 126 (2014) 52-61.

[10] D.R. Chen, D.Y.H. Pui, B.Y.H. Liu, Optimization of pleated filter designs using finite-element numerical model, Aerosol Sci. Technol. 23 (1995) 579-590.

[11] L. Del Fabbro, J.C. Laborde, P. Merlin, L. Ricciardi, Air flows and pressure drop modeling for different pleated industrial filters, Filtr. Sep. 35-40 (2002).
[12] P. Tronville, R. Sala, Minimization of resistance in pleated-media filter designs: empirical and CFD approaches, HVAC\&R Res. 9 (1) (2003) 95-106.

[13] A. Subrenat, J. Belletre, P. Le Cloirec, 3D numerical simulations of flows in a cylindrical pleated filter packed with activated carbon cloth, Chem. Eng. Sci. 58 (2003) 4965-4973.

[14] L. Spielman, S.L. Goren, Model for predicting pressure drop and filtration efficiency in fibrous media, J. Environ. Sci. Technol. 2 (1968) 279-287.

[15] Z. Feng, Z. Long, Q. Chen, Assessment of various CFD models for predicting airflow and pressure drop through pleated filter system, Build. Environ. 75 (2014) 132-141.

[16] L.F. González, A. Joubert, Y. Andrès, M. Liard, C. Renner, L. Le Coq, Filtration performances of HVAC filters for PM10 and microbial aerosols - influence of management in a lab-scale air handling unit, Aerosol Sci. Technol. 50 (6) (2016) 555-567 